\title{
USING SECONDARY RAW MATERIALS IN LIGHTWEIGHT OPEN-STRUCTURE CONCRETE WITH GOOD UTILITY PROPERTIES
}

\author{
Martin Sedlmajer*, Jiří Zach, Jan Bubeník \\ Brno University of Technology, Faculty of Civil Engineering, Centre AdMaS, Purkyňova 139, 61200 Brno, \\ Czech Republic \\ * corresponding author: sedlmajer.m@fce.vutbr.cz
}

\begin{abstract}
The paper presents the results of research in lightweight concrete with open structure made using a lightweight porous foam-glass aggregate produced from recycled glass powder. The goal was to develop lightweight concrete. In order to achieve the best possible properties while reducing binder content, the concrete was reinforced with by-product fibres, which helped reduce the weight of the concrete while delivering satisfactory mechanical properties. In the paper are proposed lightweight concrete with open structure made using foam-glass aggregate. Mechanical, thermal-insulating and acoustic properties were determined on lightweight concrete. Designed concrete is only made of crushed lightweight foam-glass aggregate with a combination of Portland cement with the option of adding recycled PET fibres. The new concretes possess a very good ratio of thermal insulation to mechanical properties as well as good sound absorption.
\end{abstract}

KEYWORDS: Lightweight concrete, lightweight aggregate, recycled fibres, thermal insulation.

\section{INTRODUCTION}

Concrete is nowadays one of the most widespread building materials and is indispensable for modern civil engineering. As the industry develops, hand in hand with the performance requirements for building materials, lightweight concrete has assumed a position where it cannot be replaced by any other kind of concrete. Lightweight concrete combines thermal insulation and acoustic properties with good mechanical properties and thus can be used in the construction of new types of single-layer structures with multifunctional properties. The reduced bulk density of this concrete saves material and energy during construction.

Depending on the requirements, there are several methods of manufacturing lightweight concrete. The most common means of weight reduction is using a lightweight filler instead of a dense aggregate. This filler is usually a lightweight aggregate. It can be natural or artificially manufactured. Artificial aggregates are used especially in cases where no sources of natural aggregate are available. One such material is foam glass, which is made from recycled glass powder.

Foam glass is manufactured artificially and is a very good source of lightweight aggregate. There are several varieties of lightweight foam glass aggregate, depending on manufacturing technology. They can be round pellets or sharp, angular particles produced by crushing larger sheets of foam glass. Both methods yield different fractions, which are then separated into broad or narrow according to need. This is important for optimal formula design, specifically, the correct particle size distribution.
Foam-glass aggregate has properties that make it suitable for use in both reinforced and non-reinforced applications, specifically fills, foundation insulation, or concrete aggregate [1, where it provides a considerable weight reduction and alters both fresh- and hardenedstate properties. The aggregate reduces bulk density and thus improves thermal insulation properties far above traditional concrete that uses natural dense aggregate [2]. A disadvantage of foam-glass aggregate are typically poorer mechanical properties, resulting from the reduced bulk density because aggregate is a dominant component of every concrete and the main provider of mechanical properties. Lightweight concretes with foam-glass aggregate can also be used in places where ordinary dense concrete is unsuitable, e.g. lightweight structures, thermal insulation and eliminating thermal bridges [3], improving fire resistance [4, etc. It still preserves all of the benefits of concrete, the most important being its mouldability.

\section{Test miXtures AND METHODOLOGY}

The research was performed with a lightweight crushed foam-glass aggregate produced by Refaglass s.r.o. It is an angular aggregate made by crushing larger pieces of foam glass and separating them by desired fraction. The feedstock for foam glass manufacturing is recycled glass powder, most often types of bottle glass that are difficult to use elsewhere in the glass industry. In addition to glass powder, another important ingredient for foam glass manufacturing is the foaming agent, which causes expansion at high temperatures (around $900^{\circ} \mathrm{C}$ ) in electric furnaces. The Refaglass aggregate 


\begin{tabular}{lccccccc}
\hline Component/Mixture No. & 1 & 2 & 3 & 4 & 5 & 6 & 7 \\
\hline Portland cement [kg] & 250 & 200 & 150 & 130 & 100 & 130 & 100 \\
Aggregates from foam glass 4-16 mm [1] & 1000 & 1000 & 1000 & 1000 & 1000 & 1000 & 1000 \\
Polycarboxylate ether superplasticizer $[\mathrm{kg}]$ & 2 & 1.6 & 1.2 & 1 & 0.8 & 1 & 0.8 \\
Water & 106 & 61 & 57 & 53 & 51 & 53 & 65 \\
PET fibres $[\mathrm{kg}]$ & - & - & - & - & - & 6.5 & 5.0 \\
\hline
\end{tabular}

TABLE 1. Mixtures of lightweight concrete.

used in this research was of a $4-16 \mathrm{~mm}$ fraction (particle size of 4 to $16 \mathrm{~mm}$ ). This fraction was used in the manufacturing of the experimental lightweight concretes with open structure. Drawing on previous research, the mixtures of the new concretes were designed. There were 7 mixtures in total, out of which mixtures 1-5 contained no fibres and differed in binder content, which descended from $250 \mathrm{~kg} / \mathrm{m}^{3}$ down to $100 \mathrm{~kg} / \mathrm{m}^{3}$. Mixtures 6 and 7 contained recycled PET fibres provided by CIUR a.s. at the amount of $5 \%$ of cement weight. Plasticiser content was uniform in all mixtures as well; $0.8 \%$ of cement weight. Table 1 shows the composition of the mixtures.

The lightweight concretes were observed for key properties so as to compare their mixtures in fresh and hardened state. The basic properties to be observed included fresh- and hardened-state bulk density, compressive strength, and thermal conductivity.

Mixtures were produced according to the formulae described above. The following tests were performed on the fresh mixtures:

- Determination of consistency in fresh concrete EN 12350-2 [5],

- determination of bulk density in fresh state EN 12350-6 [6].

And in hardened state:

- determination of bulk density in hardened state EN 12390-7 [7],

- determination of compressive strength EN 12390-3 [8],

- determination of thermal conductivity coefficient EN 12667 [9] (according to ISO 8301),

- determination of sound absorption coefficient ISO 10534-1 [10].

The recycled PET fibres had the thickness of ca. $13 \mu \mathrm{m}$ and length of $6.3 \mathrm{~mm}$. Figure 1 shows a recycled PET fibre.

\section{Results And Discussion}

The new lightweight concretes with open structure were first tested for consistency [5] and bulk density in fresh state [6] the values are listed in Table 2 and in Figure 2

It was necessary to watch the consistency because of the danger of cement paste segregation due to the great difference between the bulk density of both

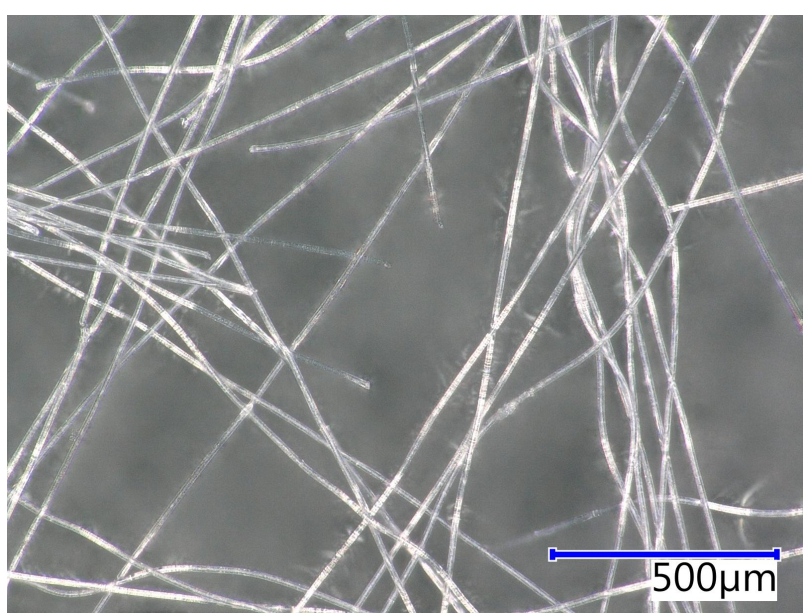

Figure 1. Detail image of PET fibre.

materials. This is why the cement paste consistency was set so as to ensure that all the foam-glass particles are completely coated in the paste without it flowing through and accumulating at the bottom.

Once correct consistency was determined, attention was paid to measuring hardened state properties, primarily compressive strength [8] and bulk density [7]. Table 3 shows the measured values.

Figure 3 shows the values of compressive strength and bulk density in a hardened state. The reduction of binder content, which entailed reducing cement content from the original $250 \mathrm{~kg} / \mathrm{m}^{3}$ (mixture 1) down to $100 \mathrm{~kg} / \mathrm{m}^{3}$ (mixture 5), which is more than a half, resulted in a loss of mechanical properties, making the concrete poorly bonded and prone to crumbling. Looking at mixture 7 , the combination of $100 \mathrm{~kg}$ of Portland cement with recycled PET fibres improved the concrete's bond and compressive strength, which reached 1.2 MPa. The benefit of the fibres is clear in this case. A similar effect can be seen in mixtures 4 and 6 , both of which contained PET fibres and thus profited from an improvement in mechanical properties, specifically compressive strength, by more than $100 \%$.

Next, the hardened concrete specimens were tested for steady-state thermal conductivity by the hot plate method (at a mean temperature of $+10{ }^{\circ} \mathrm{C}$ and a temperature gradient of $\left.10^{\circ} \mathrm{C}\right)[9$. Before that the test the specimens were dried at $105^{\circ} \mathrm{C}$ down to stable mass. The results are listed in Table 4 and plotted in Figure 4 


\begin{tabular}{lccccccc}
\hline Properties/Mixture No. & 1 & 2 & 3 & 4 & 5 & 6 & 7 \\
\hline Bulk density in fresh state [kg] & 860 & 740 & 580 & 500 & 510 & 670 & 540 \\
Slump test [mm] & 20 & 0 & 0 & 0 & 0 & 0 & 0 \\
\hline
\end{tabular}

TABLE 2. Properties of the lightweight concrete in fresh state.

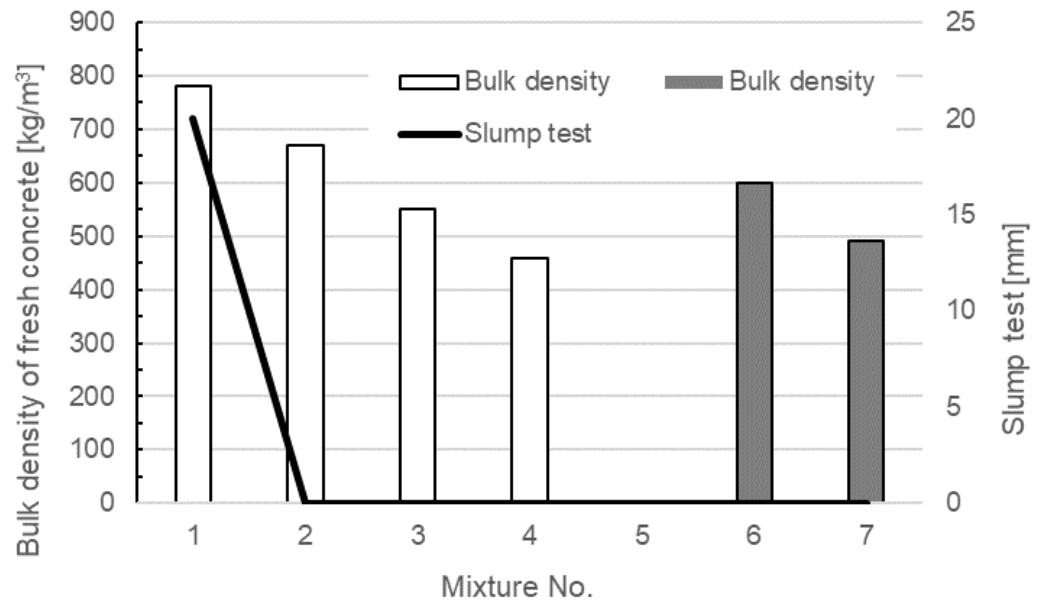

FiguRE 2. Bulk density and consistency of fresh lightweight concrete.

\begin{tabular}{lccccccc}
\hline Properties/Mixture No. & 1 & 2 & 3 & 4 & 5 & 6 & 7 \\
\hline Bulk density in hardened state $[\mathrm{kg}]$ & 780 & 670 & 550 & 460 & 500 & 600 & 490 \\
Compressive strength [MPa] & 3.6 & 2.9 & 1.5 & 0.8 & 0 & 1.8 & 1.2 \\
\hline
\end{tabular}

TABLE 3. Bulk density and Compressive strength of lightweight concrete in hardened state.

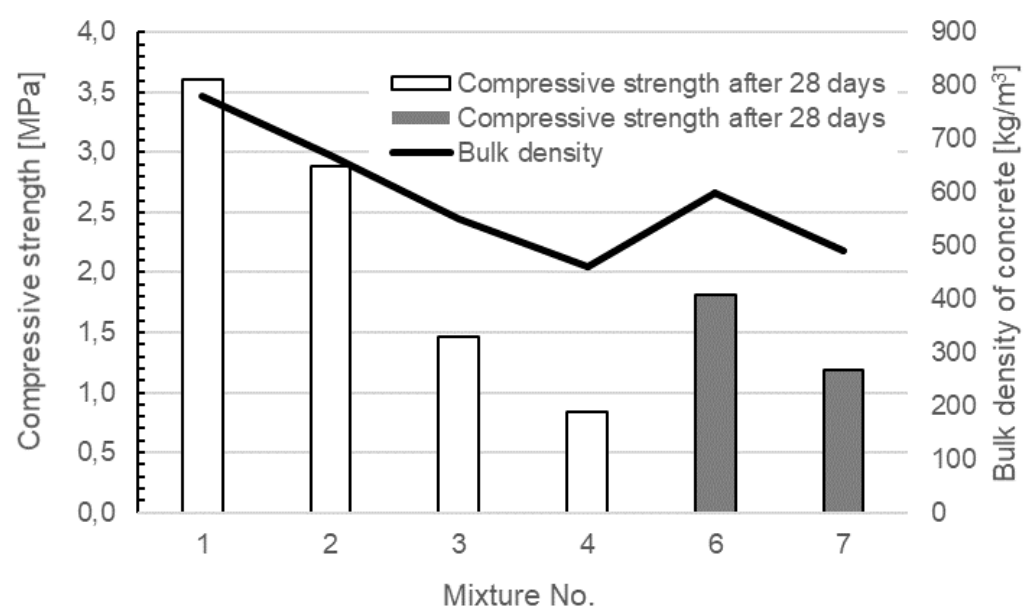

FIGURE 3. Compressive strength and bulk density of hardened lightweight concrete.

\begin{tabular}{lccccccc}
\hline Properties/Mixture No. & 1 & 2 & 3 & 4 & 5 & 6 & 7 \\
\hline Thermal conductivity coefficient $[\mathrm{W} /(\mathrm{m} \cdot \mathrm{K})]$ & 0.1529 & 0.1419 & 0.1223 & 0.1112 & 0 & 0.1214 & 0.1013 \\
\hline
\end{tabular}

TABLE 4. Thermal conductivity coefficient of lightweight concrete in hardened state. 


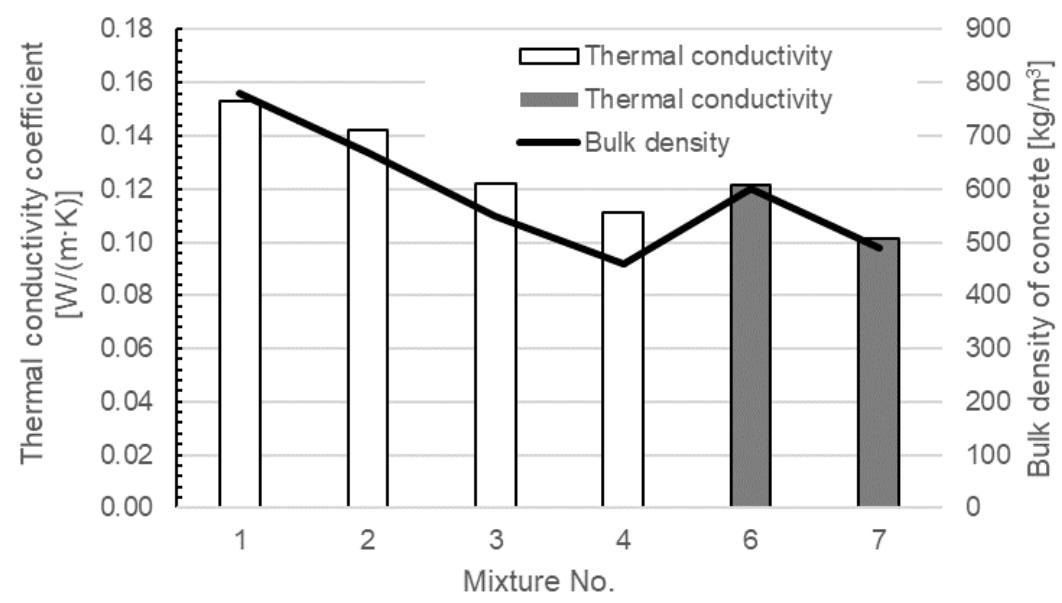

FiguRE 4. Thermal conductivity coefficient and bulk density of hardened lightweight concrete.

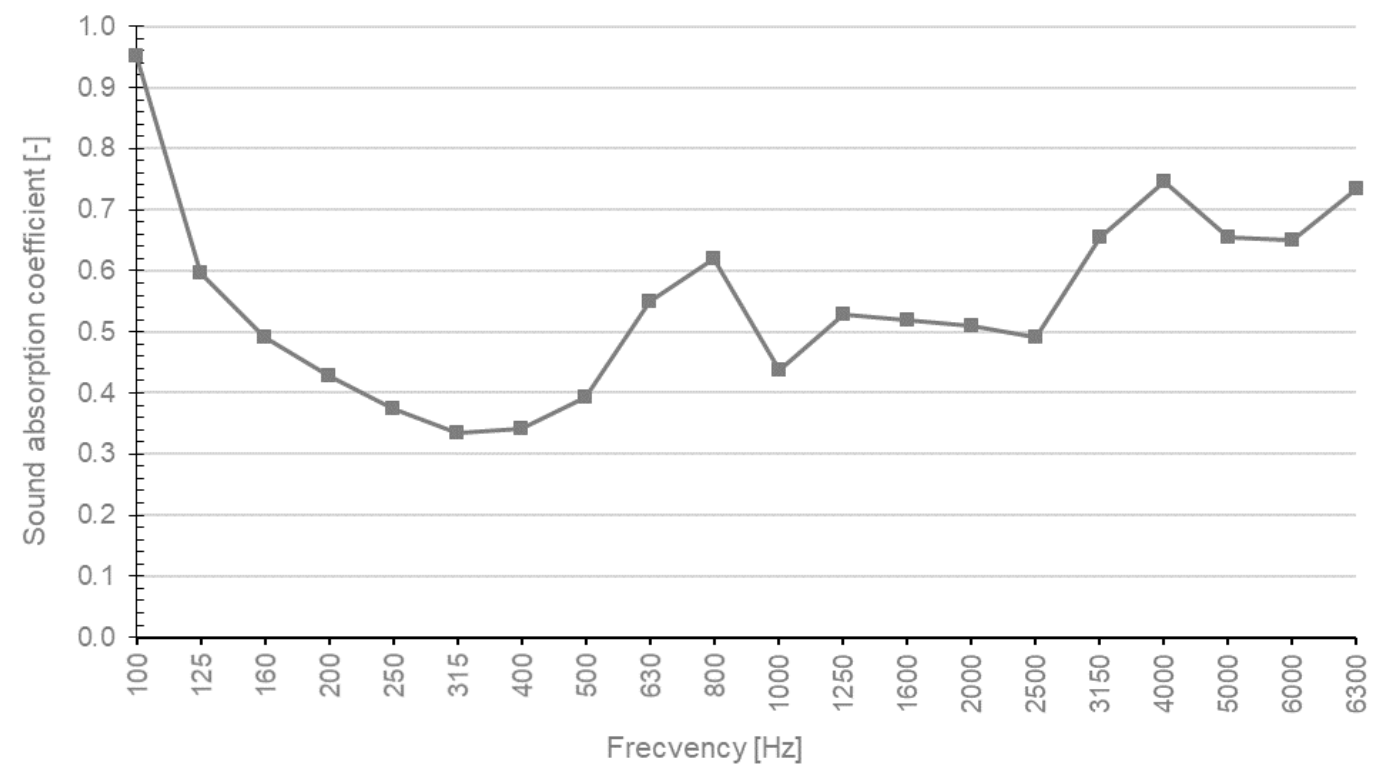

FIGURE 5. Sound absorption coefficient of hardened lightweight concrete 2.

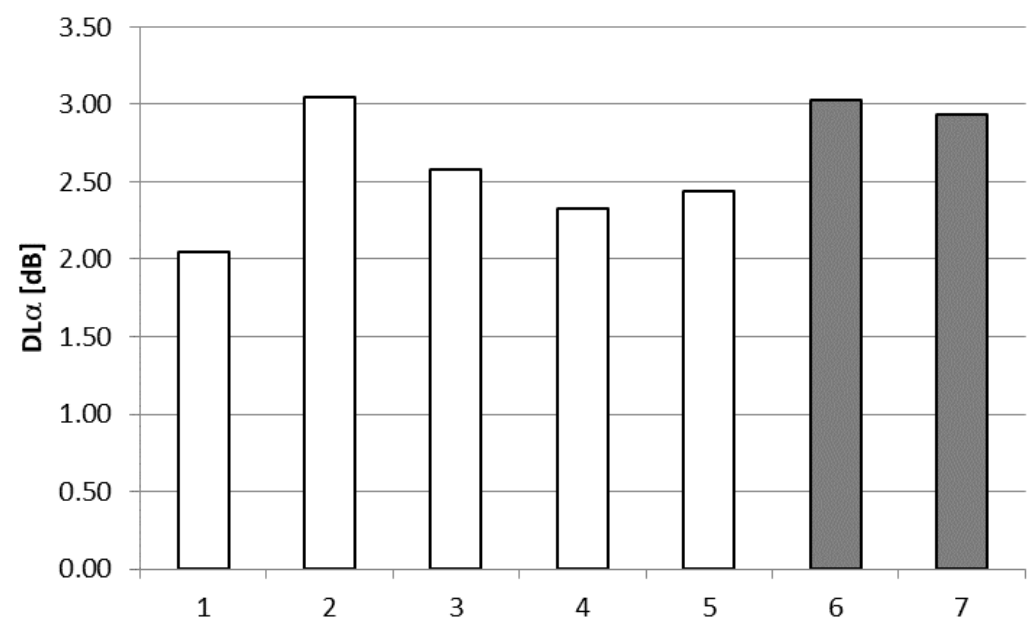

FIGURE 6. Overview of the calculated single-number values of sound absorption ČSN EN 1793. 
The results of thermal conductivity tests do not show any major effect of the fibres on thermal conductivity. As could be expected, however, what matters more is cement content.

The last parameter was the sound absorption coefficient, which expresses how well a material can absorb incoming acoustic energy. The measurements were performed using an acoustic interferometer according to ISO 10534-1 [10]. The measurement was made within 100-6300 Hz in one-third octave bands. The measured values were used in the calculation of single-number values of sound absorption $D L_{\alpha}[\mathrm{dB}]$ in accordance with results are listed in Figure 6. The progress of the sound absorption coefficient is plotted in Figure 5. The results show that mixtures 2 and 6 perform the best.

\section{Conclusions}

Lightweight crushed foam-glass aggregate can be used for manufacturing open-structure concrete with a good ratio of thermal insulation and mechanical properties. The results show that a reduced amount of cement results in poorer mechanical properties, but better thermal insulation. Reducing the cement content down to $100 \mathrm{~kg} / \mathrm{m}^{3}$ resulted in a weak, insufficiently bonded concrete.

The addition of recycled PET fibres to the mixture with $130 \mathrm{~kg}$ of cement raised its compressive strength by $125 \%$ from $0.8 \mathrm{MPa}$ to $1.8 \mathrm{MPa}$. Mixture 7 with $100 \mathrm{~kg}$ of cement and PET fibres had compressive strength of 1.2 MPa. This corresponds to a mixture without fibres with a cement content of ca. $140 \mathrm{~kg}$ of cement. It can thus be said that the addition of PET fibres brought a dramatic improvement of the concrete's properties and enabled a significant reduction of cement content without damaging the mechanical properties. In mixture 7 the reduction of cement content and addition of fibres further reduced the concrete's thermal conductivity. Its final value was $0.1013 \mathrm{~W} /(\mathrm{m} \cdot \mathrm{K})$, which makes this concrete suitable for constructing structures with excellent thermal insulation properties.

The newly developed lightweight concrete also shows very good acoustic properties (compared to ordinary dense concrete); mixtures 2 and 6 performed the best in this regard.

\section{ACKNOWLEDGEMENTS}

This paper was written under the project No. LO1408 "AdMaS UP - Advanced Materials, Structures and Technologies", supported by the Ministry of Education, Youth and Sports under the "National Sustainability Programme I" and project FV20086 "Development of light new-age building materials with utilization of light-weight aggregate based on waste glass powder" supported by the Ministry of Industry and Trade.

\section{REFERENCES}

[1] M. Limbachiya, M. S. Meddah, S. Fotiadou. Performance of granulated foam glass concrete. Construction and building materials 28(1):759-768, 2012. DOI:10.1016/j.conbuildmat.2011.10.052

[2] M. B. Janetti, T. Plaz, F. Ochs, et al. Thermal conductivity of foam glass gravels: A comparison between experimental data and numerical results. Energy Procedia 78:3258-3263, 2015. DOI:10.1016/j.egypro.2015.11.713

[3] S. Real, M. G. Gomes, A. M. Rodrigues, J. A. Bogas. Contribution of structural lightweight aggregate concrete to the reduction of thermal bridging effect in buildings. Construction and Building Materials 121:460470, 2016. DOI:10.1016/j.conbuildmat.2016.06.018.

[4] C.-G. Go, J.-R. Tang, J.-H. Chi, et al. Fire-resistance property of reinforced lightweight aggregate concrete wall. Construction and Building Materials 30:725-733, 2012. DOI:10.1016/j.conbuildmat.2011.12.081.

[5] European standard EN 12350-2 - Testing fresh concrete - Part 2: Slump-test. European standard, 2009.

[6] EN 12350-6 - Testing fresh concrete - Part 6: Density. European standard, 2009.

[7] European standard EN 12390-7 - Testing hardened concrete - Part 7: Density of hardened concrete. European standard, 2009.

[8] European standard EN 12390-3 - Testing hardened concrete - Part 3: Compressive strength of test specimens. European standard, 2009.

[9] European standard EN 12667 - Thermal performance of building materials and products - Determination of thermal resistance by means of guarded hot plate and heat flow meter methods - Products of high and medium thermal resistance. European standard, 2001.

[10] ISO 10534-1 Acoustics - Determination of sound absorption coefficient and impedance in impedance tubes - Part 1: Method using standing wave ratio. European standard, 1999. 